\title{
Long-term results of surgical resection of lung metastases from soft tissue sarcoma : A single center experience
}

\section{Nevala, Riikka}

2019-08

Nevala , R, Jäämaa , S, Tukiainen, E, Tarkkanen, M, Räsänen , J , Blomqvist, C \& Sampo , M 2019 , ' Long-term results of surgical resection of lung metastases from soft tissue sarcoma : A single center experience ' , Journal of Surgical Oncology , vol. 120 , no. 2 , pp. 168-175 . https://doi.org/10.1002/jso.25504

http://hdl.handle.net/10138/327001

https://doi.org/10.1002/jso.25504

unspecified

acceptedVersion

Downloaded from Helda, University of Helsinki institutional repository.

This is an electronic reprint of the original article.

This reprint may differ from the original in pagination and typographic detail.

Please cite the original version. 
Riikka Nevala MD, PhD1,2 Sari Jäämaa MD, PhD1,2 Erkki Tukiainen MD, PhD2,3 Maija Tarkkanen MD, PhD1,2 Jari Räsänen MD, PhD2,4 Carl Blomqvist MD, PhD1,2,5 Mika Sampo MD, PhD2,6

1 Comprehensive Cancer Center, Helsinki University Hospital (HUH), Helsinki, Finland

2 Medical Faculty, University of Helsinki, Helsinki, Finland

3 Department of Plastic Surgery, Helsinki University Hospital, Helsinki, Finland

4 Department of Pulmonary and Esophageal Surgery, Helsinki University Hospital, Helsinki, Finland

5 Department of Oncology, Örebro University Hospital, Örebro, Sweden

6 Department of Pathology, University of Helsinki and HUSLAB, Helsinki, Finland

Corresponding author

Mika Sampo, Department of Pathology,

University of Helsinki and HUSLAB, HUH P.O.

Box 400, HUH-00029 Helsinki, Finland.

Email: mika.sampo@hus.fi 
Abstract

Background: A single-institution experience of pulmonary metastasectomy in soft tissue sarcoma (STS) was retrospectively reviewed. Our specific aim was to examine, whether the resection of pulmonary metastases could be curative. We also compared overall survival (OS) of patients after complete or incomplete pulmonary resection and nonsurgical treatment.

Methods: Between 1987 and 2016, 1580 patients were treated for STS with curative intent by Soft Tissue Sarcoma Group at Helsinki University Hospital, Finland. Three hundred forty-seven patients (22\%) developed advanced disease and 130 STS patients $(9 \%)$ developed pulmonary metastases as first systemic relapse. Seventy four patients (5\%) were operated for lung metastases.

Results: Fifty-five patients (42\%) had a complete and 19 (15\%) incomplete resection. Fifty-six (43\%) were unoperated. Median OS after complete or incomplete metastasectomy, chemotherapy, or best supportive care was 22, 18, 8 , and 5 months, respectively. Twelve patients (9\%) developed no further metastases and are alive with no evidence of disease. Disease-free survival (DFS) for completely resected patients was $17 \%$ at 5 years. All long-term survivors had oligometastatic disease and they underwent one to three complete metastasectomies.

Conclusions: Complete pulmonary metastasectomy in STS results in 5 years DFS in nearly one-fifth of patients. Most of these patients are probably cured.

\section{KEYWORDS}

long-term survival, metastasectomy, pulmonary metastases, soft tissue sarcoma 


\section{INTRODUCTION}

Soft tissue sarcomas (STS) are rare malignant neoplasms comprising approximately $1 \%$ of all cancers. Despite optimal local treatment and satisfactory local control rates, $20 \%$ to $30 \%$ of STS patients develop metastases. The prognosis of metastatic disease is usually poor with a median survival of 12 to 17 months,1-3 and overall 5-year survival of patients with metastatic STS has not improved during the last decades. In the Thames Cancer Registry for 1985-1994 and 1995-2004, 5-year survival rates for metastatic STS were only $13 \%$ and $15 \%$, respectively. 4 Few chemotherapy regimens are active in metastatic STS. Doxorubicin is the most important chemotherapeutic agent, 5 providing a median survival of only approximately 1 year.6

Solitary pulmonary metastasis and oligometastases are a common manifestation in STS. Aggressive surgical management of pulmonary metastasis, including repeat metastasectomies, has achieved an important role in STS treatment but without level I or II evidence.1,7-14 Approximately $25 \%$ of patients are alive 5 years after surgery of pulmonary metastases, but most studies do not reveal whether these patients live with or without relapse.4 No randomized trials to compare survival after surgery and nonsurgical treatment have been published.4 The population from which patients were selected for pulmonary metastasectomy and the prognosis unresected patients are seldom reported. The percentage of patients undergoing pulmonary metastastasectomy has reported to be between $31 \%$ and $58 \% .1,11,15$

Surgical resection has been the recommended treatment for all STS patients presenting with metastases exclusively to the lungs at our department since 1987. The object of the present study was to assess the proportion of long-term survivors without evidence of disease in surgically treated patients and to compare their outcome to nonsurgically treated patients.

\section{MATERIALS AND METHODS}

\subsection{Patients}

During 1987-2016 1580 patients were treated for STS with curative intention by Soft Tissue Sarcoma Group at Helsinki University Hospital (HUH). Twenty-two percent (347) of the patients developed systemic disease during follow-up, and 145 patients (9\%) had the first systemic relapse in lungs. Fifteen patients were excluded due to relapse during adjuvant treatment (11), primary pulmonary sarcoma (2), or subtype (one rhabdomyosarcoma and one Ewing's sarcoma). The remaining 130 patients were included in the study (Figure 1), which was approved by the HUH Ethics Committee and the Ministry of Social and Health Affairs.

Demographic and clinical variables included age at diagnosis, sex, histologic type, grade, size, and location of the primary sarcoma, therapy for the primary tumor, surgical margins, possible local recurrence, and disease-free interval (DFI). At pulmonary relapse patients age, the number of nodules, possible symptoms, size of the largest nodule, and patient's performance status were collected from medical records. Surgical resection was classified as complete if all recognized disease was removed with negative margins.

\subsection{Follow-up protocol for STS patients following primary treatment with curative intention at Helsinki University Hospital}

The treatment plan of new and relapsed STS patients is made at weekly meetings of the multidisciplinary team. After primary treatment, all patients have regular follow-up. In high-grade sarcoma chest X-ray is performed every 2 months during the first 2 years, and thereafter three times annually up to 5 years. A physical examination and a magnetic resonance imaging (MRI; or computed tomography [CT]) of the primary tumor region are performed every 6 months up to 2 years and thereafter annually up to 5 years. In low-grade sarcoma, chest X-ray is performed every 4 months during the first 2 years, twice a year up to 4 years, yearly up to 7 years and thereafter at 1.5 years intervals up to 10 years. A physical examination and an MRI (or a CT) of the primary tumor region are performed yearly for 7 years and therafter at 1.5 years interval.

If pulmonary metastases are suspected, a chest CT is performed. Patients with metastases confined to lungs are recommended metastasectomy if feasible. Preoperative assessment to exclude extrathoracic disease and to assess operative risks include abdominal CT, MRI, or CT of primary tumor region and cardiac and pulmonary function tests (electrocardiogram, spirometry, and diffusion capacity). 
Overall survival (OS) was defined from the development of metastases, as defined by radiologic evidence of disease to death or last follow-up. DFI was defined as the time from primary tumor resection or from the end of adjuvant treatment to metastatic disease. In patients with pulmonary operations, disease-free survival (DFS) was defined as time from previous complete pulmonary resection to the radiologic evidence of progression. Patients dying without relapse were censored in the analysis of DFS. Normally distributed continuous variables were summarized using mean and standard deviation and compared using a t-test. Nonnormally distributed variables were summarized by median and range and compared with the Wilcoxon rank-sum test. Proportions were compared using the $\chi 2$ test. Survival data were graphically displayed as Kaplan-Meier curves. Differences between groups were assessed by the log-rank test. All statistical tests were two-sided. IBM SPSS Statistics version 23 (SPSS, Chicago, Illinois) was used for all analyses.

\section{RESULTS}

\subsection{Characteristics of patients}

The present study includes 130 STS patients, who developed pulmonary metastases as first systemic relapse after curative local treatment. No patient was lost during follow-up. Patient characteristics at primary diagnosis are presented in Table 1. The median age at diagnosis was 60 years. Median tumor size was $9 \mathrm{~cm}$. All but two tumors were high grade.

\subsection{Nonsurgical treatment}

Thirty-six patients (64\%) were treated with palliative chemotherapy and twenty patients (36\%) were treated with best supportive care (BSC) without surgery. Reasons for abstaining from surgery were insufficient performance status (19 patients), multiple pulmonary metastases (15), difficult anatomical location of metastases (15), patient's denial (4), short DFI (2), and disease progression between detection and planned surgical resection (1). Doxorubin-ifosfamid was the most common first-line regimen (16 patients) followed by single doxorubicin (six patients). No patient achieved complete response (CR), seven patients had partial response (PR), and 19 stable diseases. Nine patients received radiation therapy (RT) for pulmonary metastases. Median OS of the chemotherapy and BSC groups were 8 and 5 months, respectively. Five- and ten-year OS rate for chemotherapy group were $6 \%$ and $0 \%$ and for BSC $0 \%$ and $0 \%$, respectively.

\subsection{Surgical treatment}

Seventy-four (57\%) of the 130 patients were resected for pulmonary metastases. Fifty-two patients (70\%) had open thoracotomy as first operation, 18 (24\%) were treated with video-assisted thoracoscopy (VATS). Two patients (3\%) with bilateral disease had open thoracotomy in one side and VATS on the side and in two patients (3\%) VATS was transformed to open thoracotomy because more metastases were detected than in preoperative imaging. One patient died due complications (empyema). The operated patients were younger, with better performance status and had more often unilateral disease with fewer nodules when compared with conservatively treated patients. Characteristics of operated and unoperated patients are shown in Table 2.

\subsubsection{Incomplete resection}

Nineteen patients (15\%) were treated with incomplete surgery. In 11 patients CT did not show all metastases or pleural growth. In four patients surgery was incomplete due to the central location of metastases. Tumor cell contamination during surgery occurred in two patients (3\%) and both relapsed in the lungs. Eight patients received postoperative chemotherapy after an incomplete resection. All patients with incomplete surgery progressed. Fifteen of the 19 patients with incomplete surgery received palliative chemotherapy for progression. Median OS after incomplete surgery was 18 months (range, 2-84 months). OS was $8.6 \%$ and $0 \%$ at 5 and 10 years, respectively.

\subsubsection{Complete resection}

In 55 patients, a complete resection was achieved in the first surgery. Median OS was 22 months, (range, 6-228 months) after the first complete resection (Figure 2A). Nine patients received adjuvant chemotherapy and of these patients, two remain relapse- 
free. Forty-five (82\%) patients developed a second systemic relapse after complete resection. Twenty-two (42\%) patients developed only pulmonary metastases and 12 (24\%) of these were@@ re-resected. Complete resection in second surgery was achieved in eight patients, who all relapsed. Five of these patients developed pulmonary relapse and had a third complete resection. Two of these remain relapse-free (Figure 1). Thus, 12 patients are presently disease-free after radical surgery in 1 to 3 operations. Median follow-up time for 12 relapse-free patients was 29 months, range 8 to 105 months. DFS for completely resected patients was $17 \%$ at 5 years (Figure 2B). All systemic recurrences occured within 5 years. Median OS after the last complete pulmonary resection was 20 months, range 4 to 178 months. OS at 5 years was $20 \%$.

\subsection{Survival of patients}

Median OS of patients with BSC, chemotherapy only, incompletely and completely resected metastases were $5,8,18$, and 22 months, respectively, $\mathrm{P}<.0001$ (Figure 3). The difference between chemotherapy treatment and incomplete surgical treatment was not significant $(\mathrm{P}=.173)$.

\subsection{Prognostic factors}

Analyses of 55 radically resected patients revealed two statistically significant favorable prognostic factors for DFS: a single nodule resected at last complete pulmonary resection and DFI >1.3 years (Table 3). Patients with oligometastatic disease were the only long-term disease-free survivors (Table 3). Long-term DFS was seen, however, even after three repeated surgical resections.

\section{DISCUSSION}

Favorable outcome after surgical resection of pulmonary metastases in STS have been reported in numerous studies since the 1940s.16 The true benefit of this treatment policy is still uncertain and has been seriously questioned in the absence of randomized trials. 4

Large retrospective studies from specialist centers 1,7-9 and a systematic review4 have shown 5 -year survival between 13\% and $52 \%$ after complete resection of lung metastases. However, 5-year OS is not necessarily equal to cure due to the variable clinical course of STS. Most previous long-term studies have reported only OS, but not the proportion of patients without evidence of disease (NED). We found only two large 1,9 and two small17,18 series of metastasectomy reporting also long-term DFS. None of these reported estimated DFS at 5 or 10 years. Nine percent of patients remained NED at the end of follow-up in both of the two largest studies of 7191 and 539 patients.9 Follow-up time varied between 61 to 234 months in Billingsley's study 1 but was not reported in Chudgar's study. 9 Like in the present series (98\%), the majority of patients had high-grade sarcoma, $87 \%$ and $90 \%$, respectively.1,9 The small series of 2017 and 23 patients, 18 reported that $20 \%$ and $52 \%$ were NED, respectively, but long-term DFS was not reported.

Long-term survival after chemotherapy of advanced STS is uncommon. In a study of 2187 patients with advanced STS, the estimated OS at 5 years from first-line chemotherapy was $8 \%$ decreasing to $5.6 \%$ at 10 years. 19 Only $3 \%$ were alive 5 years after starting chemotherapy, $45 \%$ of these had either a complete or PR, and in these patients 10 -year OS was $94 \% .19$ In a retrospective investigation $7 \%$ of patients with advanced STS achieved complete remission by chemotherapy alone.20 The median DFS was 23 months and seven patients (3.5\%) were in continuing remission at the end of follow-up20 suggesting chemotherapy may occasionally be curative. The efficacy of single doxorucin has been compared with combination of doxorubicin and ifosfamide in a phase 3 study. The median follow-up of was 56 to 59 months and only $6 \%$ of patients in the doxorubicin group and $8 \%$ in the combination arm were alive and progression-free at the cut-off date.6 Thus, long-term survival with advanced STS is possible without cure, and a small proportion of nonsurgically treated metastatic may even be cured by chemotherapy.

In the present study 5-year survival without disease (DFS) was defined as a surrogate endpoint for cure. DFS for completely resected patients was $17 \%$ at 5 years. OS of these patients at 5 years was $20 \%$. Thus, about $15 \%$ of those alive at 5 years after resection were living with disease and all these died before reaching 10 years of follow-up. Since all systemic relapses occured within first 5 years of follow-up, the 17\% proportion of patients alive after five and 10 years with no evidence of disease may probably be considered cured by metastasectomy. 
Two favorable prognostic factors for 5-year DFS after complete resection of pulmonary metastasis were identified: a single nodule resected at last complete resection and a DFI over 1.3 years. Our results is in concordance with previous studies in which a single pulmonary metastatic lesion,1,7,9 DFI of greater than twelve months,1,7-9 negative resection margins at metastectomy, 1 histologic subtype of leiomyosarcoma,9 minimally invasive resection9) and younger age8 have been reported to be favorable prognostic factors after metastasectomy. The endpoint of all these previous studies has been OS, while the present study examined prognostic factors for long-term DFS. Although these two endpoints are naturally related, long-term OS in advanced STS is not always equivalent to cure, due to the variable clinical course of this disease. Oligometastatic disease, in the present series a single nodule resected at last complete resection, and up to three lesions resected at repeated surgery, was the most important predictive factor for the chance of long-term DFS. A short DFI, while being statistically significantly associated to short DFS, did not preclude the chance of being a long-term relapse-free survivor, as $11 \%$ of patients with complete metastatic resection and a DFS $<1.3$ years, were also long-term disease-free survivors.

As expected, patients treated with incomplete surgery, only chemotherapy or BSC, had a significantly worse outcome than patients with complete resection. Fifty-six patients were not operated and most of them received palliative chemotherapy. If the surgery was incomplete, the patients had no survival advantage over patients only treated with chemotherapy, although the operated patients were younger, with better performance status and had more often unilateral disease with few nodules. There is no evidence in the literature of palliative benefit from pulmonary metastasectomy, 21 but life quality after first pulmonary resection has been studied prospectively. Three months after the operation, patients had significantly more pain, dyspnea, fatigue and deteriorated physical functioning compared to preoperative state.21 Thus, if it is technically impossible to perform complete resection, our results suggest that chemotherapy should generally be preferred to surgery.

Our study has certain limitations. During 30 years time of data collection, changes occurred in the therapeutic strategies, new drugs for sarcomas were introduced, surgical, RT, and lung imaging techniques were developed which all may influence prognosis. Strengths of the study include a consistently written treatment protocol with the same policy of surgical resections for lung metastases during 30 years, and complete documentation of patient demographics, tumor characteristics, follow-up for recurrence and survival of all patients.

In conclusion, radical pulmonary metastasectomy seems to lead to permanent cure as reflected by 5-year DFS and OS in oligometastatic patients. Patients may be cured also after repeated resections. This retrospective study indicated no advantage of incomplete resection compared with nonsurgical treatment.

\section{ACKNOWLEDGEMENTS}

Outi Malkavaara is thanked for valuable assistance during preparing the manuscript. This study was supported by the Competitive Research Funding of Helsinki University Hospital and the Finnish Cancer Society. They had no role in the study design, data interpretation, or article writing.

\section{CONFLICT OF INTERESTS}

The authors declare that there are no conflict of interests.

\section{DATA ACCESSIBILITY}

Data are available on request from the authors. 


\section{REFERENCES}

1. Billingsley KG, Burt ME, Jara E, et al. Pulmonary metastases from soft tissue sarcoma: analysis of patterns of diseases and postmetastasis survival. Ann Surg. 1999;229:602-610.

2. Billingsley KG, Lewis JJ, Leung DH, et al. Multifactorial analysis of the survival of patients with distant metastasis arising from primary extremity sarcoma. Cancer. 1999;85:389-395.

3. Gronchi A, Miceli R, Colombo C, et al. Primary extremity soft tissue sarcomas: outcome improvement over time at a single institution. Ann Oncol. 2011;22:1675-1681.

4. Treasure T, Fiorentino F, Scarci M, et al. Pulmonary metastasectomy for sarcoma: a systematic review of reported outcomes in the context of Thames Cancer Registry data. BMJ Open. 2012;2:2.

5. Bramwell VH, Anderson D, Charette ML, et al. Doxorubicin-based chemotherapy for the palliative treatment of adult patients with locally advanced or metastatic soft tissue sarcoma. Cochrane Database Syst Rev. 2003;3:CD003293.

6. Judson I, Verweij J, Gelderblom H, et al. Doxorubicin alone versus intensified doxorubicin plus ifosfamide for first-line treatment of advanced or metastatic soft-tissue sarcoma: a randomised controlled phase 3 trial. Lancet Oncol. 2014;15:415-423.

7. Wigge S, Heissner K, Steger V, et al. Impact of surgery in patients with metastatic soft tissue sarcoma: a monocentric retrospective analysis. J Surg Oncol. 2018;118:167-176.

8. Dossett LA, Toloza EM, Fontaine J, et al. Outcomes and clinical predictors of improved survival in a patients undergoing pulmonary metastasectomy for sarcoma. J Surg Oncol. 2015;112:103-106.

9. Chudgar NP, Brennan MF, Munhoz RR, et al. Pulmonary metastasectomy with therapeutic intent for soft-tissue sarcoma. J Thorac Cardiovasc Surg. 2017;154:319-330.

10. Li Y, Zhang W, Li S, Tu C. Clinical efficiency of repeated pulmonary metastasectomy in sarcoma patients with recurrent pulmonary metastasis: a meta-analysis. J Cancer Res Ther. 2018;14:S457-S462.

11. Gadd MA, Casper ES, Woodruff JM, et al. Development and treatment of pulmonary metastases in adult patients with extremity soft tissue sarcoma. Ann Surg. 1993;218:705-712.

12. van Geel AN, Pastorino U, Jauch KW, et al. Surgical treatment of lung metastases: the European Organization for Research and Treatment of Cancer-Soft Tissue and Bone Sarcoma Group study of 255 patients. Cancer. 1996;77:675-682.

13. Pastorino U, Buyse M, Friedel G, et al. Long-term results of lung metastasectomy: prognostic analyses based on 5206 cases.

The International Registry of Lung Metastases. J Thorac Cardiovasc Surg. 1997;113:37-49.

14. Verazin GT, Warneke JA, Driscoll DL, et al. Resection of lung metastases from soft-tissue sarcomas. A multivariate analysis. Arch Surg. 1992;127:1407-1411.

15. Rehders A, Hosch SB, Scheunemann P, et al. Benefit of surgical treatment of lung metastasis in soft tissue sarcoma. Arch Surg. 2007;142:70-75.

16. Alexander J, Haight C. Pulmonary resection for solitary metastatic sarcomas and carcinomas. Univ Hosp Bull. 1946;12:117.

17. Garcia Franco CE, Algarra SM, Ezcurra AT, et al. Long-term results after resection for soft tissue sarcoma pulmonary metastases. Interact Cardiovasc Thorac Surg. 2009;9:223-226.

18. Chen F, Fujinaga T, Sato K, et al. Significance of tumor recurrence before pulmonary metastasis in pulmonary metastasectomy for soft tissue sarcoma. Eur J Surg Oncol. 2009;35:660-665.

19. Blay JY, van Glabbeke M, Verweij J, et al. Advanced soft-tissue sarcoma: a disease that is potentially curable for a subset of patients treated with chemotherapy. Eur J Cancer. 2003;39:64-69.

20. Wiklund T, Saeter G, Strander H, et al. The outcome of advanced soft tissue sarcoma patients with complete tumour regression after either chemotherapy alone or chemotherapy plus surgery. The Scandinavian Sarcoma Group experience. Eur J Cancer.

1997;33:357-361.

21. Welter $S$, Schwan $A$, Cheufou $D$, et al. Midterm changes in quality of life: a prospective evaluation after open pulmonary metastasectomy. Ann Thorac Surg. 2013;95:1006-1011. 


\section{Table 1}

Description of primary tumour, patient and treatment characteristics of 130 patients with pulmonary dissemination as first systemic relapse

\begin{tabular}{|c|c|}
\hline Characteristics & No. of patients \\
\hline \multicolumn{2}{|l|}{ Sex } \\
\hline Male & $68(52)$ \\
\hline Female & $62(48)$ \\
\hline \multicolumn{2}{|l|}{ Age at Diagnosis (years) } \\
\hline Median & 60 \\
\hline Range & $17-91$ \\
\hline \multicolumn{2}{|l|}{ Local Recurrence prior to metastases } \\
\hline No & $117(90)$ \\
\hline Yes & $13(10)$ \\
\hline \multicolumn{2}{|l|}{ Primary Tumor Site } \\
\hline Lower extremity & $60(46)$ \\
\hline Upper extremity & $14(11)$ \\
\hline Trunk & $40(31)$ \\
\hline Head\&neck & $3(2)$ \\
\hline Other sites ${ }^{a}$ & $13(10)$ \\
\hline \multicolumn{2}{|l|}{ Grade according to French system } \\
\hline Intermediate & $2(2)$ \\
\hline High & $128(98)$ \\
\hline \multicolumn{2}{|l|}{ Depth } \\
\hline Superficial & $20(15)$ \\
\hline Deep & $110(85)$ \\
\hline \multicolumn{2}{|l|}{ Tumour size $(\mathrm{cm})^{\mathrm{b}}$} \\
\hline Median & 9 \\
\hline Range & $2-50$ \\
\hline \multicolumn{2}{|l|}{ Histological subtype } \\
\hline UPS & $45(35)$ \\
\hline Liposarcoma & $7(5)$ \\
\hline Synovial sarcoma & $17(13)$ \\
\hline Leiomyosarcoma & $19(15)$ \\
\hline MPNST & $7(5)$ \\
\hline Fibrosarcoma & $7(5)$ \\
\hline Neurofibrosarcoma & $2(2)$ \\
\hline Myxofibrosarcoma & $7(5)$ \\
\hline Epithelioid sarcoma & $3(2)$ \\
\hline Sarcoma NOS & $12(9)$ \\
\hline Extraskeletal OS & $4(3)$ \\
\hline \multicolumn{2}{|l|}{ Margin } \\
\hline Intralesional & $15(12)$ \\
\hline Marginal & $77(59)$ \\
\hline Wide & $38(29)$ \\
\hline \multicolumn{2}{|l|}{ Radiation therapy to primary tumour } \\
\hline Yes & $84(65)$ \\
\hline No & $46(35)$ \\
\hline \multicolumn{2}{|l|}{ Chemotherapy to primary tumour } \\
\hline Yes & $36(28)$ \\
\hline No & $94(72)$ \\
\hline
\end{tabular}

Number in parenthesis refers to percentage.

MPNST, malignant peripheral neural sheath tumor; NOS, not otherwise spesified; OS, osteosarcoma; UPS, undifferentiated pleomorphic sarcoma.

${ }^{a}$ One in testis, two in prostate, one in uterus, eight in retroperitoneum and one intra-abdominally.

${ }^{\mathrm{b}}$ Size was not determined in four tumours. 
Table 2

Description of tumour, patient and treatment characteristics of 130 patients at first systemic relapse to lungs by treatment category

\begin{tabular}{|c|c|c|c|c|c|}
\hline & $\begin{array}{c}\text { Complete } \\
\text { metastasectomy }\end{array}$ & $\begin{array}{c}\text { Incomplete } \\
\text { metastasectomy }\end{array}$ & $\begin{array}{c}\text { Palliative } \\
\text { chemotherapy }\end{array}$ & $\begin{array}{l}\text { Best supportive } \\
\text { care }\end{array}$ & $\mathrm{P}^{\mathrm{a}}$ \\
\hline & $\mathrm{n}=55$ & $\mathrm{n}=19$ & $\mathrm{n}=36$ & $\mathrm{n}=20$ & \\
\hline \multicolumn{6}{|l|}{ Disease-free interval (years) } \\
\hline Median & 1.6 & 0.8 & 0.5 & 0.7 & 0.005 \\
\hline Range & $0.1-10.8$ & $0.5-4.7$ & $0.1-3.3$ & $0.3-7.1$ & \\
\hline \multicolumn{6}{|l|}{ Age at Systemic Relapse } \\
\hline Median & 54 & 64 & 62 & 84 & $<0.001$ \\
\hline Range & $18-83$ & $19-83$ & $21-85$ & $36-91$ & \\
\hline Laterality & & & & & $<0.001$ \\
\hline Unilateral & 41 & 9 & 1 & 8 & \\
\hline Bilateral & 14 & 10 & 35 & 12 & \\
\hline No of nodules at first relapse & & & & & 0.011 \\
\hline 1 & 28 & 0 & 1 & 6 & \\
\hline 2 & 13 & 6 & 1 & 5 & \\
\hline 3 & 7 & 3 & 1 & 0 & \\
\hline 4 & 4 & 0 & 4 & 0 & \\
\hline$>4$ & 3 & 4 & 11 & 1 & \\
\hline Unknown & 0 & 6 & 18 & 8 & \\
\hline Symptoms & & & & & 0.002 \\
\hline Yes & 4 & 2 & 7 & 9 & \\
\hline No & 51 & 17 & 29 & 11 & \\
\hline Largest nodule at first relapse $(\mathrm{mm})$ & & & & & 0.11 \\
\hline $6-10$ & 8 & 2 & 1 & 0 & \\
\hline $11-20$ & 20 & 2 & 8 & 3 & \\
\hline $21-30$ & 14 & 5 & 4 & 0 & \\
\hline $31-40$ & 3 & 2 & 0 & 3 & \\
\hline $41-50$ & 4 & 3 & 1 & 3 & \\
\hline $51-60$ & 1 & 0 & 2 & 2 & \\
\hline $61-70$ & 0 & 1 & 0 & 2 & \\
\hline$>70$ & 0 & 1 & 1 & 0 & \\
\hline Unknown & 5 & 3 & 19 & 7 & \\
\hline WHO PS & & & & & $<0.001$ \\
\hline 0 & 42 & 11 & 12 & 1 & \\
\hline 1 & 13 & 8 & 16 & 5 & \\
\hline 2 & 0 & 0 & 8 & 12 & \\
\hline 3 & 0 & 0 & 0 & 2 & \\
\hline
\end{tabular}

PS, performance status.

${ }^{a} \mathrm{X} 2$ test or Fisher's exact test. 
Table 3

Disease-free survival at 5 years after the last complete pulmonary surgery for patients having complete pulmonary surgery $(\mathrm{n}=$ 55)

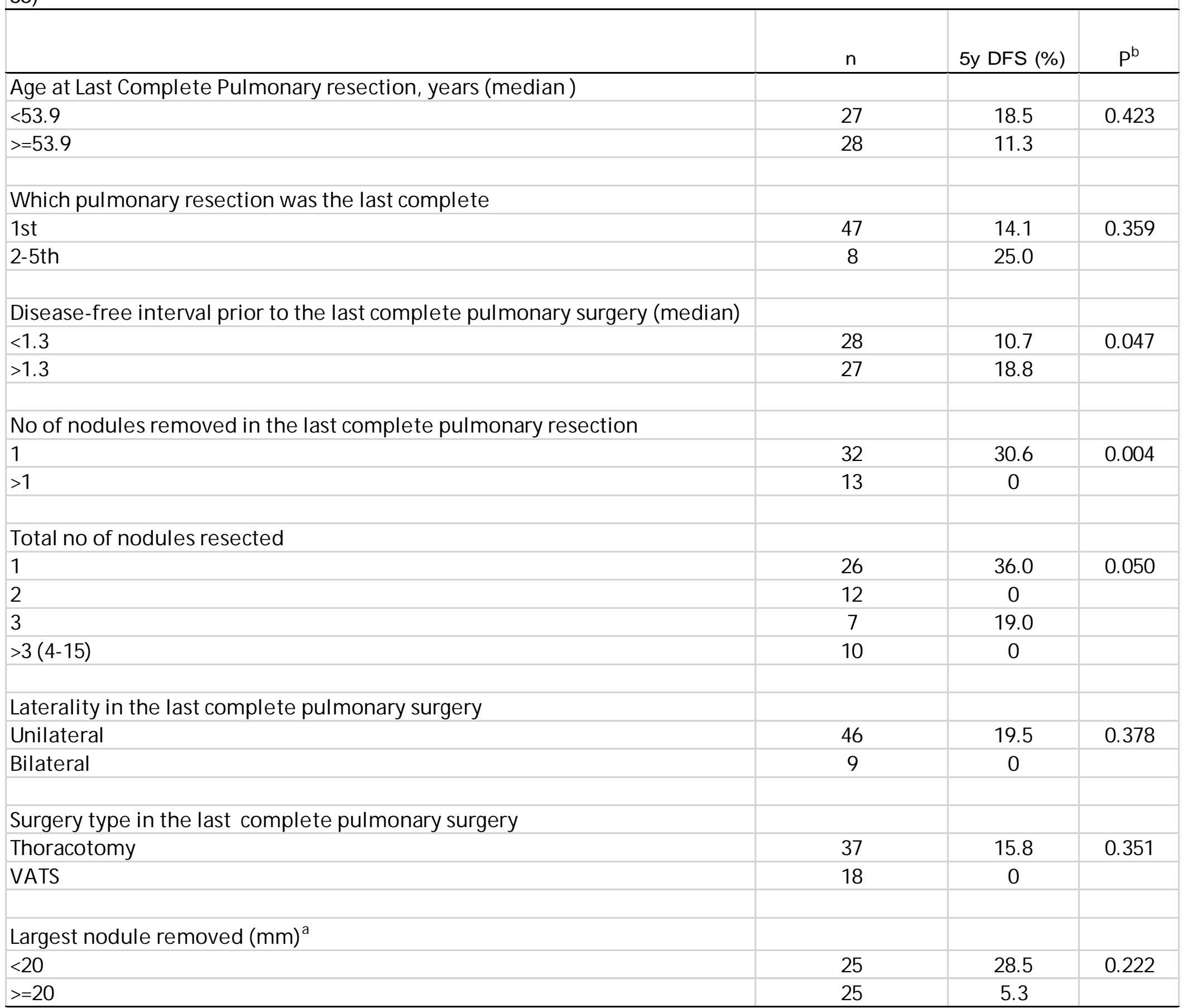

DFS, disease-free survival; VATS, video-assisted thoracoscopic surgery

${ }^{\mathrm{a}}$ Size not reported in 5 cases.

${ }^{\mathrm{b}} \mathrm{x} 2$ test or Fisher's exact test. 


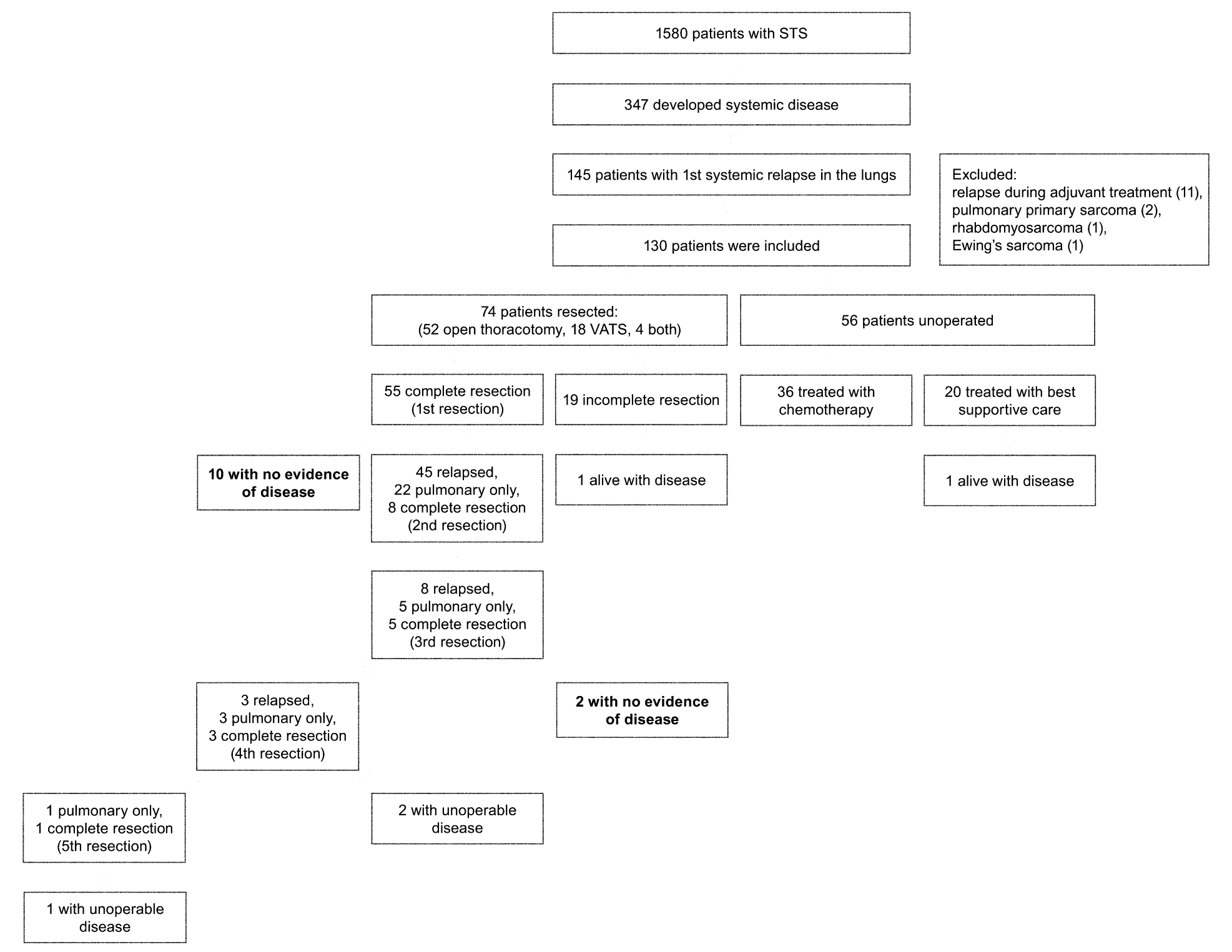

FIGURE 1 Flow chart of the patient population. STS, soft tissue sarcoma; VATS, video-assisted thoracoscopy 
A

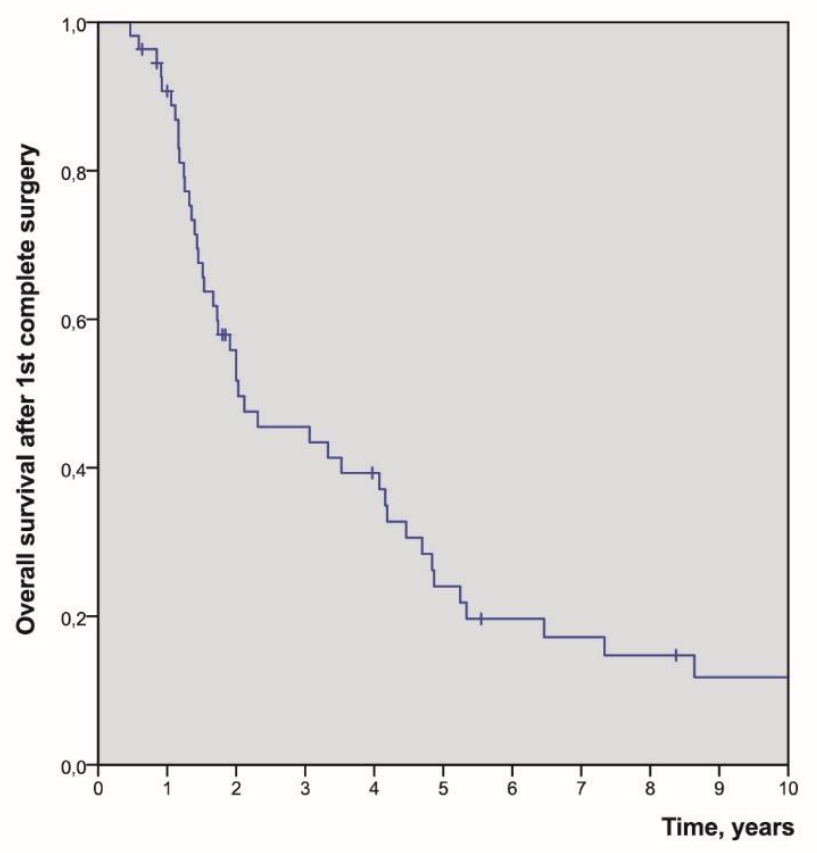

B

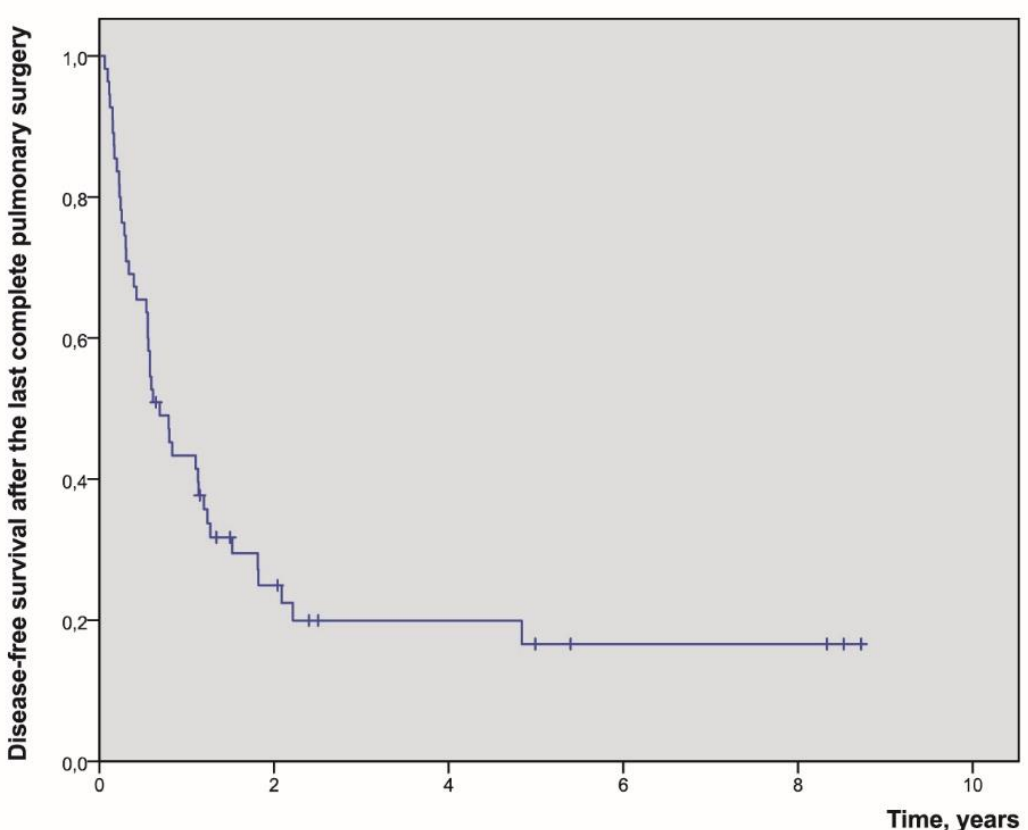

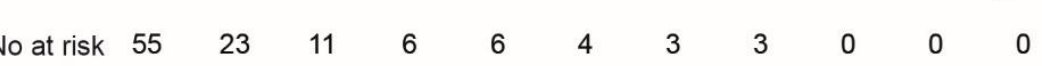

FIGURE 2 A, Overall survival after first complete metastasectomy. B, Disease-free survival after the last complete metastasectomy 


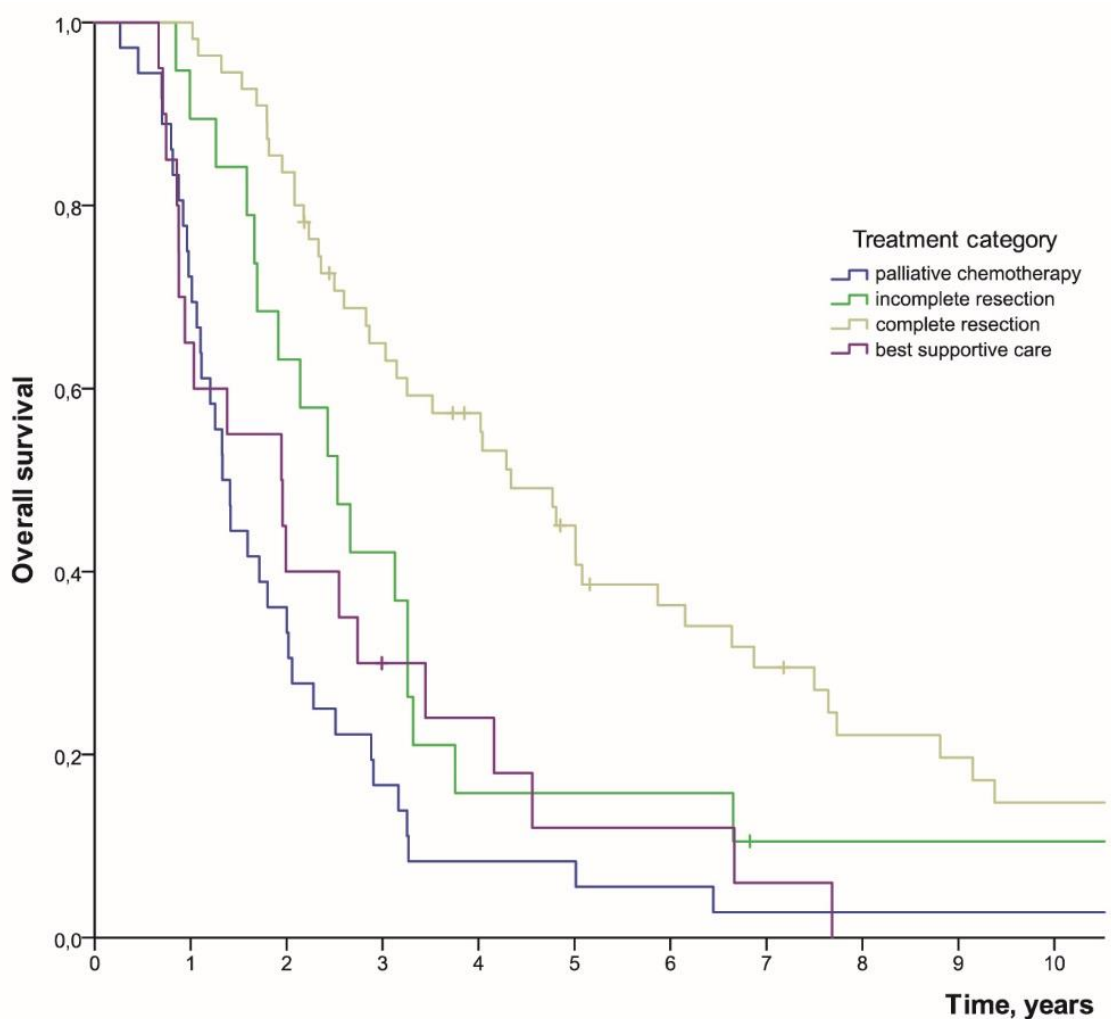

No at risk

$\begin{array}{lccccccccccc}\text { Complete resection } & 55 & 48 & 26 & 22 & 18 & 11 & 8 & 7 & 6 & 4 & 4 \\ \text { Incomplete resection } & 19 & 13 & 6 & 2 & 1 & 1 & 1 & 1 & 0 & 0 & 0\end{array}$

$\begin{array}{llllllllllll}\text { No resection+ pall. CT } & 36 & 12 & 6 & 3 & 3 & 2 & 2 & 1 & 0 & 0 & 0\end{array}$

BSC

FIGURE 3 Overall survival by treatment category of the 130 patients. BSC, best supportive care; CT, chemotherapy 